\title{
Hannah Arendt: el pensar en el espacio politico y en la cultura
}

\author{
Dora Elvira García González
}

C

uando Hannah Arendt en "El pensar y las reflexiones morales"1 toma como objeto de sus reflexiones el caso Eichmann, ${ }^{2}$ alude al fenómeno de los actos criminales y monstruosos, no imputables a la maldad o patología del agente ni a una convicción ideológica determinada de aquel que los llevó a cabo. Lo que se manifestaba y se evidenciaba en el juicio del dirigente nazi, era una incapacidad auténtica para pensar. ${ }^{3}$ El pensar como hábito de examinar y de reflexionar acerca de todo lo que acontezca puede ser una actitud de tal naturaleza que condicione a los hombres contra el mal.

El argumento arendtiano señala que esa ausencia nada tenía que ver con elementos demoniacos ni con supuestas perversiones de la naturaleza. La privación y la desaparición del juicio, conlleva la amnesia sobre la capacidad de distinguir el bien y el mal. La ligereza como se considera el mal se debe a la renuncia de la capacidad valorativa y la negligencia del factor humano. Ese mal es cometido por la ausencia de pensamiento, dicha supresión no afecta a las facultades intelectuales sino a la capacidad de valorar la acción. No se trata de idiotas en el sentido patológico del término, sino de un idiota moral incapaz de juzgar la moralidad de sus actos: los realiza y punto. ${ }^{4}$

${ }^{1}$ Hannah Arendt, "El pensar y las reflexiones morales", en De la historia a la acción. Barcelona, Paidós, 1995, pp. 109-137.

${ }^{2}$ Adolf Eichmann, teniente coronel de la ss y uno de los mayores criminales del holocausto, es raptado en Argentina y trasladado a Jerusalén para someterlo a un juicio (1961) ante un tribunal internacional capaz de juzgar crímenes contra la humanidad. Arendt es la reportera del caso para el periódico New Yorker. Ella constata en el juicio un modelo de racionalidad propio de personas como el enjuiciado, poniendo en tela de juicio dicho modo de pensar.

${ }^{3}$ H. Arendt, "El pensar y las reflexiones morales", en op. cit., p. 109.

${ }^{4}$ Arendt en un primer momento sostiene la radicalidad del mal, sobre todo en Orígenes del totalitarismo, sin embargo, más tarde, con el caso Eichmann, sostiene 
Este caso sirve de pretexto a Arendt para incidir en algunos rubros esenciales de su teoría: "el pensar y el juicio", que, en el caso del artículo citado, relaciona con las reflexiones morales.

El pensamiento de Eichmann se mostraba lleno de contradicciones, así como plagado de "clichés, frases hechas y adheridas a lo convencional, códigos estandarizados de conducta y de expresión". 5 La superficialidad del acusado "hacía imposible vincular la incuestionable maldad de sus actos a ningún nivel más profundo de enraizamiento o motivación". ${ }^{6}$ El responsable era totalmente corriente, del montón, ni demoniaco ni monstruoso, simplemente banal. No había en él ningún signo de convicciones o de fines ideológicos ni de motivaciones especialmente malignas, de ahí que esa manera de actuar no fuera estupidez, sino más bien una falta de reflexión suplida con el lenguaje estereotipado.

La manera de proceder como alguien estereotipado, con frases hechas, con códigos de conducta establecidos y con expresiones estandarizadas -según Arendt- nos protege "frente a la realidad, es decir, frente a los requerimientos que sobre nuestra atención pensante ejercen todos los acontecimientos y hechos, en virtud de su misma existencia, ya que si fuera necesario pensar en cada caso, acabaríamos agotados". ${ }^{7}$

La ausencia de reflexión y de conciencia de Eichmann manifestaba así la inexistencia total de pensamiento.

En este breve espacio, nuestras reflexiones se orientarán hacia el pensar y el juicio llevado a cabo en el espacio público, valorando su importancia en la teoría arendtiana para, más adelante, al seguir el curso de las reflexiones de nuestra filósofa, enlazarlos y referirlos a la cultura. Ambos, el ámbito político y el de la cultura, se relacionan en el espacio público.

más bien la banalidad del mal. Parece que al menos esta segunda versión resulta más esperanzadora. Arendt afirma en una carta a Jaspers: "No sé qué sea realmente el mal en su dimensión radical, pero me parece que, en cierto modo, tiene que ver con el siguiente fenómeno: la reducción de los hombres en cuanto hombres a seres absolutamente superfluos, lo que significa [...] convertir en superflua su misma cualidad de hombres". Con esa superficialidad el hombre ha muerto aun antes de su muerte biológica. Esa superficialidad de lo humano hace posible todo y se deriva de ahí la posibilidad de saltar por encima de todo límite imaginable, ya que se rescinde todo principio de moralidad o de legitimidad. Es el reino de lo arbitrario.

${ }^{5} \mathrm{H}$. Arendt, "El pensar y las reflexiones morales", en op. cit., p. 110.

${ }^{6} \mathrm{H}$. Arendt, La vida del espíritu. Madrid, Centro de Estudios Constitucionales, 1984 , p. 14.

${ }^{7}$ H. Arendt, "El pensar y las reflexiones morales", en op. cit., p. 110. 
Para nuestra autora en cuestión, la existencia de la conciencia y del juicio es necesaria para lograr un ámbito político, y por ende un espacio cultural, ya que estas dos realidades están imbricadas entre sí, se pertenecen mutuamente porque "no es el saber o la verdad lo que está en juego, sino el juicio y la decisión, el intercambio de opiniones referentes a la esfera de la vida pública y del mundo común y la decisión sobre cuál manera de acción debe tomarse en ella". ${ }^{8}$ Éste es el único campo donde es posible la realización humana plena, libre y en comunión con los demás. El juicio es la nota central y punto de convergencia de las reflexiones arendtianas; el pensar es un diálogo interno sin fin, es autoconciencia. Al menos -señala Arendt- el estar ligado o comprometido a un diálogo interno consigo mismo pone límites en la conducta de cada quien, de ahí que vivir la vida de la mente tenga implicaciones morales.

Volviendo al caso, según Arendt, parecía que Eichmann había carecido de ese diálogo interno, por lo que, la reportera, sostenía que nadie que hubiera poseído la conciencia personal que acompaña el hábito de pensar, podía haber llevado a cabo dichos actos, ni hubiera cumplido con tal precisión las demandas terroríficas de la función burocrática que realizaba el enjuiciado. De ese modo, para la filósofa de Könisberg, la conciencia puramente secular, la conciencia del hombre autoconsciente que vive con sus obras, puede salvaguardarse en contra del mal político, aunque la cuestión es que la vida de las personas se realiza en el ámbito de las acciones, que es el ámbito político, el de la libertad; y sólo ahí las personas se realizan de mejor manera.

Arendt sostiene que en un momento dado, aunque la integridad personal consciente puede detener a su poseedor de estar implicado con el mal, es improbable que tome alguna acción política positiva si se es un individuo aislado, ya que, al no estar suficientemente ligado al mundo público, al mundo político, al mundo común y al ámbito de la libertad y del reconocimiento de los otros, no cuenta con los elementos suficientes para enfrentar tal situación. En esa etapa la conciencia está relacionada con el self y su integridad, no con el mundo, marcando así la diferencia entre ser un buen hombre, en un sentido socrático, es decir, quedar limpio de hacer el mal; y un buen ciudadano, que significa asumir responsabilidades compartidas para el mundo público. El salto entre el ámbito privado y el público sólo se da al asumir la pluralidad de los hombres (elemento central de la teoría de Arendt). De ahí entonces que la postura socrática, de volver y estar consigo mismo, sea completada por

${ }^{8}$ H. Arendt, "Crisis en la cultura", en Between Past and Future. Nueva York, Penguin Books, 1968, p. 223. 
la influencia kantiana, en relación con la "mentalidad agrandada" asumida por la pensadora alemana.

Lo más importante a defender en el mundo -para nuestra filósofa en cuestión-, es evitar el mal, sea quien sea quien lo sufre, la obligación de todos es prevenirlo. El deber político de las personas es tomar la responsabilidad para el mundo, aunque, en casos límite (Jaspers) y en situaciones extremas -como por ejemplo el totalitarismo-, es posible retirarse hacia la integridad personal para recuperarse o salvarse. Así, el self como último criterio de la conducta moral es políticamente un tipo de medida de emergencia. La necesidad de pensar sólo puede ser satisfecha pensando; los pensamientos de ayer satisfarían hoy ese deseo sólo porque podemos pensar de nuevo. La mirada al pasado es en Arendt la condición de la reflexión que liga con el presente a través de la capacidad de pensar.

Arendt resalta el ejemplo socrático por resultar ilustrativo; se presenta como paradigma de inicio en el pensar debido a las tres caracterizaciones que ella hace del filósofo griego cuando apela a los calificativos que él mismo o sus coetáneos le aplicaron. ${ }^{9}$ El primer apelativo con el que es nombrado hace referencia al despertar de las personas, de ahí el nombre "tábano", al aguijonear, incitando a la reflexión y al examen crítico para hacer pensar y examinar los asuntos propios. El segundo sobrenombre de "comadrona" se le atribuía por el hecho de purgar a la gente de sus opiniones (embriones malformados) y prejuicios no analizados que impiden pensar, o por saber librar a los otros de sus pensamientos, de las implicaciones de sus opiniones, así como de los prejuicios que impiden pensar. Motejado también como "torpedo" por asemejarse al pez que paraliza y entumece por contacto, al lograr contagiar a los demás a través del tocamiento ${ }^{10} \mathrm{o}$ la proximidad; quiere esto decir que aquellos que son rozados quedan imbuidos e infundidos de sus cuestionamientos.

El pensar socava todos los criterios establecidos y aparta de los pensamientos congelados e inamovibles, ciertamente cómodos, con los cuales es posible valerse mientras se está adormecido. Cada palabra que utilizamos en un lenguaje común es como un pensamiento congelado que el pensar debe descongelar para averiguar el sentido original.

El pensamiento es como el viento, espabila y despierta, hace entender la necesidad de afrontar las perplejidades, por ello y en este sentido, el pensamiento es destructivo; ${ }^{11}$ es como un huracán que "barre todos los signos es-

${ }^{9}$ Cf. H. Arendt, La vida del espíritu, pp. 202-203.

${ }^{10} \mathrm{H}$. Arendt, "El pensar y las reflexiones morales", en op. cit., pp. 123-124.

${ }^{11}$ Ibid., p. 125. 
tablecidos". ${ }^{12}$ La vida que vale la pena vivir es la que es examinada por cada uno de nosotros acorde con nosotros mismos, por ello, Arendt, sostiene, parafraseando a Sócrates: es mejor que la lira esté desafinada y que desentone de mí, y que un sinnúmero de hombres disientan de mí, antes que yo desentone conmigo mismo y me contradiga. ${ }^{13}$ Somos uno con nosotros mismos, de ahí que sea menester este acuerdo con nosotros mismos; ahí se asume y se fortifica la alteridad, posibilitando el salto de mí hacia lo otro. De este modo, conciencia $^{14}$ y alteridad conforman las características de la pluralidad del mundo y del ego humano. En mi unicidad -dice Arendt-, se inserta la diferencia, ${ }^{15}$ alteridad y diferencia son características importantes del mundo de la pluralidad y son también condiciones para la existencia del self del hombre. Donde quiera que haya pluralidad hay diferencia.

Arendt distingue entre conciencia y pensamiento, este último la necesita y la presupone. En la primera se da un diálogo interno entre uno mismo y la conciencia propia, que dice qué hacer y de qué arrepentirse (lo que fue la voz de Dios antes del lumen naturale o de la razón práctica kantiana). Lo que se teme de esa conciencia es la anticipación de la presencia de un "testigo que espera al volver a casa", que está siempre inquiriendo sobre nuestras acciones cotidianas. El no pensar significa no regresar a casa, ni someter las cosas y los eventos que realizamos a un examen crítico. ${ }^{16}$

Por su parte "el pensar se ocupa de objetos que están ausentes y alejados de la directa percepción de los sentidos; un objeto de pensamiento es siempre una re-presentación, es decir, algo o alguien que en realidad está ausente y sólo está presente a la mente que, en virtud de la imaginación, lo puede hacer presente en forma de imagen. ${ }^{17} \mathrm{El}$ yo pensante piensa sobre algo, no

${ }^{12}$ Ibid., p. 127.

${ }^{13}$ Ibid., p. 130.

${ }^{14}$ Arendt señala: "llamamos conciencia literalmente a 'conocer consigo', al curioso hecho de que en cierto sentido yo soy para mí mismo aunque apenas aparezca ante mí, lo cual indica que el 'ser uno' de Sócrates no es tan simple como parece, yo soy solo para los otros y también para mí mismo [...] En mi unicidad se inserta una diferencia" (H. Arendt, La vida del espíritu, p. 214).

${ }^{15} \mathrm{H}$. Arendt, "El pensar y las reflexiones morales", en op. cit., p. 132.

${ }^{16}$ Cf. H. Arendt, La vida del espíritu, p. 222.

17 Ibid., p. 115. Esta cuestión la relaciona Arendt con la concepción que san Agustín tiene de la "imagen" en De trinitate (Lb. XI), en donde describe la transformación que sufre cualquier objeto dado a los sentidos para así devenir en objeto de pensamiento. La percepción sensorial, 'exterior', es seguida de una visión 'interior', una imagen destinada a hacer presente 'el cuerpo ausente' en la representación. La imagen, representación de algo ausente, se almacena en la memoria y se convierte en objeto de pensamiento en cuanto es deliberadamente recordada, por lo cual, es fundamental que lo que permanece en la memoria, es decir, la re-presentación, que es una 
piensa algo, es un acto dialéctico, una forma de diálogo silencioso. ${ }^{18} \mathrm{El}$ pensamiento opera con lo invisible, con representaciones de objetos ausentes. ${ }^{19}$ El juicio, entonces, requiere de la imaginación, así como de la reflexión. ${ }^{20} \mathrm{El}$ juzgar se ocupa de objetos y casos particulares a la mano. ${ }^{21}$

La facultad de pensar que sostiene Arendt debe ser adscrita a todas las personas. No es posible esperar de la actividad de pensar ningún mandato o proposición moral, ni algún código de conducta. En este punto se ubican, según su parecer, las doctrinas dominadoras y totalizantes inaceptables, las cuales muestran que la experiencia de las crisis de este siglo "enseña el simple hecho de que no hay criterios generales que determinen nuestros juicios inequívocamente, ni reglas generales bajo las cuales subsumir los casos particulares con algún grado de certeza". Por lo dicho, entonces "debemos tratar de pensar, juzgar y actuar sin esos sustentos", ${ }^{22}$ y hacerlo por nosotros mismos según la máxima de sensus communis.

Sin embargo, el pensar es peligroso, puede derivarse de él un riesgo insuperable de la actividad de pensar: el nihilismo, como la otra cara del conservadurismo, es la negación de valores vigentes. Es necesario localizar los elementos que hicieron innecesario seguir pensando, y que condujeron al nihilismo que no proviene ni emerge de la convicción socrática de que una vida sin examen no tiene objeto vivirla. ${ }^{23}$ Llegamos entonces al punto de partida. Cualquier examen crítico supone el paso por la etapa de cuestionamiento o negación, al menos temporal, de las aseveraciones, y pone en marcha creencias o afirmaciones nuevas.

cosa y otra distinta lo que aparece al recordar (cap. 3). Arendt señala que san Agustín es consciente de que el pensamiento va más allá y traspasa el dominio de toda imaginación posible (cap. 8). También señala que el de Hipona parece sugerir que la razón puede alcanzar lo totalmente ausente sólo porque la mente, en virtud de la imaginación y sus re-presentaciones, sabe cómo hacer presente lo que está ausente y cómo manejar estas ausencias en la rememoración, es decir, en el pensamiento. En Lectures on Kant's Political Philosophy, Arendt señala que en cuanto a la imaginación, Kant dice que es la facultad de hacer presente lo que es ausente, es decir, la facultad de representación."La imaginación es la facultad de representar en la intuición un objeto que no está en sí presente" en la Crítica de la razón pura (B151), o la "facultad de percepción en la ausencia de un objeto" en Antropología desde un punto de vista pragmático, \&28.

${ }^{18}$ H. Arendt, La vida del espíritu, p. 219.

${ }^{19}$ Ibid., p. 224.

${ }^{20} \mathrm{H}$. Arendt, ed., Lectures on Kant's Political Philosophy. Chicago, Universidad de Chicago, 1982, pp. 68 y ss.

${ }^{21} \mathrm{H}$. Arendt, La vida del espíritu, p. 224.

22 "The Crisis Character of Modern Society" en Christianity and Crisis, 26/9, $30 \mathrm{de}$ mayo, 1966, p. 113.

${ }^{23}$ Cf. Platón, Apología. Madrid, Aguilar, 1966. 
El pensar resulta central, ya que, al "sustraer a la gente de los peligros del 'examen crítico' se le enseña a adherirse inmediatamente a cualquiera de las reglas de conducta vigentes en una sociedad determinada y en un momento dado", ${ }^{24}$ de modo tal que se deja de pensar por sí mismo. El examen detenido de las reglas lleva a la perplejidad, a la vacilación, de manera más aguda y cuestionante que tener las reglas y sólo subsumir bajo ellas los particulares, sólo hacer lo que se manda sin tomar decisiones propias y pensadas. Como consecuencia, se cambian algunos códigos supuestamente aferrados y consistentes, y su mudanza resulta de su somnolencia ante el mundo. El pensar acompaña la existencia al tener que ver con conceptos tales como justicia, felicidad, templanza, placer y todo aquello que ocurre en la vida. El significado político y moral del pensar aflora en momentos de crisis, cuando las cosas parecen desmoronarse. Ahí en esos momentos, el pensar ya no está al margen de lo político y de lo común sino que tiene que engarzarse con ellos para dar respuestas bien pensadas. Aquellos que piensan ponen resistencia a realizar de modo irreflexivo aquello en lo que no están de acuerdo. En ese pensamiento se cuestionan todas las certezas y se hace imposible para el que piensa estar de acuerdo con la muchedumbre, y adoptar opiniones aceptadas generalmente sin escrutinio. Este proceder tiene un efecto liberador que recae sobre la facultad del juicio. Tal capacidad juzga los particulares sin necesidad de subsumirlos bajo reglas generales, se enseñan y aprenden en hábitos. ${ }^{25}$

El pensar libera la "facultad del juicio", la más política de las habilidades humanas mentales. La habilidad de juzgar y distinguir lo bueno de lo malo, lo bello de lo feo, puede ser vital en los momentos cuando los chips o los elementos de sujeción se cayeron, de tal modo que tal habilidad puede prevenir catástrofes. ${ }^{26}$

Debido a que somos libres todos necesitamos juicios, en esta libertad podemos encontrar la fuente de los criterios y los juicios que necesitamos. No es posible establecer reglas morales por razonamientos lógicos, sin embargo, podemos desarrollar una facultad del juicio. Por ello, según Hannah Arendt, ante situaciones políticas extremas, es preciso pensar y juzgar en vez de aplicar categorías, fórmulas y slogans. Sócrates afirma que nadie podía hacer el

${ }^{24} \mathrm{H}$. Arendt, "El pensar y las reflexiones morales", en op. cit., p. 127.

${ }^{25} \mathrm{Idem}$. Esa facultad de juzgar particulares no coincide con la facultad de pensar. El pensar opera como lo invisible, con representaciones de cosas que están ausentes, el juzgar se ocupa de particulares y cosas a la mano, sin embargo, ambos están interrelacionados de forma tal como "se interconectan conciencia moral y conciencia del mundo".

${ }^{26} \mathrm{Cf}$. H. Arendt, "El pensar y las reflexiones morales", en op. cit., p.137 y La vida del espíritu”, p. 224. 
mal voluntariamente, por el status ontológico: el mal es ausencia de bien, algo que no es. Por eso, socráticamente, Arendt señala que el mal y la ausencia de pensamiento significan que los hombres no están enamorados de la belleza, de la justicia y la sabiduría, por ello son incapaces de pensar; así a la inversa, los que aman el examen crítico, los que filosofan, serían incapaces de hacer el mal. ${ }^{27}$

Es relevante el énfasis que hace el pensamiento arendtiano sobre el juicio. La historia ya se había encargado de mostrarle a la filósofa alemana que adherirse a fórmulas rígidas no es una respuesta adecuada a los dilemas en la política. Lo mejor que podemos hacer son juicios concretos, tratando de evitar que nuestro juicio sea distorsionado por máximas y reglas que no son apropiadas. ${ }^{28}$

\section{II}

Pensar es pues, un proceso sin fin que produce resultados no establecidos, es como la red de Penélope, el diálogo interno consigo mismo nunca termina. De ahí la diversidad de pensamientos aun sobre las mismas cuestiones. Por su parte los ciudadanos están en un mundo común, compartiendo un grupo de instituciones mundanas, permitiendo siempre un espacio entre los individuos. Pensar es individual, el juicio es en común, es una virtud política, un columpio entre ambos polos. Es necesario hablar por los otros, si no, sería traicionar lo que para Arendt es la política, la arena, el espacio público donde los seres humanos manifiestan su pluralidad. En este sentido, la unanimidad es cuestionable, produce desconfianza, y no es probable ni deseable. La instauración de la unanimidad y la creencia de que todos los hombres racionales deben pensar similarmente sobre cuestiones públicas, son las distorsiones que Arendt considera son causadas en el pensamiento político por el dominio de la tradición filosófica antipolítica y totalitaria. La unanimidad es un signo de la detención y paralización de la actividad de pensar, manifestado en el pensamiento de la masa, al reflejar fanatismo y superficialidad. ${ }^{29}$

La afirmación de que los seres humanos son plurales, significa que pueden alcanzar a formar un espacio entre ellos, y en ese espacio podemos ver su

${ }^{27}$ Cf. H. Arendt, La vida del espíritu, p. 210.

${ }^{28}$ Ronald Beiner, "Interpretive Essay", en H. Arendt, Lectures on Kant's Political Philosophy, parte II, p. 111.

${ }^{29}$ H. Arendt, "To save the Jewish Homeland", en Ron H. Feldman, ed., The Jew as Pariah: Jewish Identity and Politics in the Modern Age. Nueva York, Grove Press, 1978, p. 182. 
mundo común desde diferentes puntos de vista. Así, las personas pueden hablar sobre sus asuntos comunes, cada quien desde su propia perspectiva. Arendt es muy clara en este punto cuando afirma que la pluralidad hace posible un espacio público entre ellos. Ese ámbito es el lugar de la discusión y la acción. Es ése el lugar propio de la excelencia humana y donde surge el reconocimiento, concediendo dignidad y significación sobre lo que aparece, es la arena donde se humaniza al mundo por la interminable habla. Este ámbito público es donde la realidad se devela y donde la libertad hace que nos movamos entre las diferentes perspectivas y desde las diferentes visiones de los hombres plurales. Ellos logran visualizar su mundo común desde la pluralidad de posiciones. Tal pluralidad es importantísima porque permite a la realidad ser experienciada. El entendimiento de la libertad se presenta como la experiencia de aquella realidad que puede ser vista desde los diferentes puntos de vista de los hombres plurales. La pérdida de esta multiplicidad de puntos de vista equivale a perder la realidad y es la situación en la que se da el totalitarismo. Por ello el lugar propio de la excelencia humana es el espacio público.

Es ahí en ese espacio donde las cosas pueden ser vistas en su multiplicidad y variedad de aspectos, sin cambiar su propia identidad, ya que aquellos que son recogidos alrededor de ellos, saben que ven igualdad en completa diversidad. Es donde la realidad mundana puede aparecer. Esto sucede en la políti$\mathrm{ca}$, en esa esfera pública donde todo puede aparecer y ser discutido para develar la realidad. En la ausencia de un discurso genuino, plural y público no se puede tener bien tomada la realidad, ni la garantía de la salud política. La realidad se devela en ese reino público de la política conformada por hombres plurales. Precisamente porque somos plurales la acción en la política no es cuestión de héroes solitarios, sino la interacción de pares, por tal pluralidad. La cuestión no es reglamentar, sino interactuar con los otros. La pluralidad maximiza la igualdad. La preeminencia de lo público sobre lo privado encara la virtud política dominante en este espacio, a saber, el coraje.

Arendt insiste en que no hay necesidad para la gente ser semejante o pensar semejantemente para poder vivir juntos. Lo que une a las personas es que viven en el mismo espacio público, compartiendo sus preocupaciones comunes y reconociéndose mutuamente como iguales pero a la vez diferentes. Ya lo decíamos líneas arriba, la unanimidad no es probable ni deseable, es una señal de que la gente dejó de pensar, y se le considera entonces masificadamente, como bien lo apreció nuestra filósofa ante los regímenes totalitarios.

El espacio público ofrece a los ciudadanos la oportunidad de moverse entre los diferentes puntos de vista de los participantes, al hablar sobre cuestiones comunes. Ahí comparten sus propias visiones y desarrollan sus opiniones en el curso de sus conversaciones. Es preciso que haya un libre discurso para que se posibilite la libertad de pensamiento. 
Ese ámbito público, abierto e iluminado, es donde nos conjuntamos con los pares a deliberar sobre cuestiones sobre ese mundo común. Se deja de lado la dominación, la sujeción a la necesidad y a lo biológico, se aparta de lo oscuro.

El ejercicio de las mentes sobre asuntos comunes, en ese espacio público, hace que se vean tales cuestiones de manera natural, desde diferentes puntos de vista, posibilitando la formación de opiniones diferentes. ${ }^{30}$ Las personas ven lados desemejantes del mismo mundo. Precisamente lo que el espacio público ofrece entre los ciudadanos es la oportunidad de moverse entre diferentes puntos de vista al hablar sobre asuntos comunes. ${ }^{31}$ Esta continua habla y pensamiento, en la presencia de otros, posibilita a los ciudadanos desarrollar lo que Arendt, tomando prestado el término de la Crítica del juicio de Kant, llama "mentalidad agrandada". Ésta les da a dichos ciudadanos la oportunidad de considerar la realidad, en un sentido común, como el tipo de autoconciencia personal par excellence. Además del sentido común, el intercambio de opiniones hacen posible el juicio. ${ }^{32}$ La facultad del juicio requiere el firme sostén en la multiplicidad de lados de la realidad que viene de compartir un mundo con otros. ${ }^{33}$

El pensar no puede llevarse a cabo sin intercambiar el pensamiento de cada persona en público, es lo que habilita a cada uno para agrandar la mente de cada quien al incorporar las visiones personales de los demás. ${ }^{34}$

El pensamiento crítico depende del uso de la razón de cada quien, retroalimentando así la vida pública al cuestionar a las autoridades y debatir afirmaciones aceptadas y haciendo posible juicios imparciales.

Aquella zanja entre el pasado y el futuro de la que habla Arendt, sólo puede ser ocupada por los hombres pensantes. ${ }^{35}$

\section{III}

Si para Arendt el juicio aparece en el espacio político, ahí también se manifiesta la cultura, es el espacio común, el lugar del discurso y la acción. El mundo

${ }^{30}$ Cf. H. Arendt, On Revolution. Harmondsworth, Penguin, 1973, p. 225.

${ }^{31}$ Cf. H. Arendt, Men in Dark Times. Londres, Jonathan Cape, 1970, pp. 24-25.

${ }^{32}$ Que había sido el sujeto del tercer volumen no escrito de The life of the Mind (vol. II pp. 242-243 y 255-272).

${ }^{3} C f$. H. Arendt, "Crisis en la cultura", en op. cit., pp. 220-223 y R. Beiner, "Interpretive Essay", en op. cit., pp. 89-156.

${ }^{34}$ Cf. H. Arendt, ed., Lectures on Kant's Political Philosophy, pp. 38-39 y 40-42.

${ }^{3}$ Cf. H. Arendt, "Prefacio: la brecha entre el pasado y el futuro", en Entre el pasado y el futuro. Barcelona, Península, 1996, pp. 19 y ss. 
puede ser resumido con el encabezado de cultura. Cultura y política se pertenecen mutuamente. El intercambio se lleva a cabo en ese espacio público donde la cultura está puesta en juego.

La posición socrática presentada por Arendt y que tomamos en un primer momento, parece completarse con lo que Kant propone en la Crítica del juicio, al señalar que no es suficiente estar de acuerdo consigo mismo sino en ser capaz de "pensar poniéndose en lugar de los demás", es decir (a través de), la mentalidad agrandada o modo de pensar amplio". ${ }^{36}$ En esta tercera crítica, Kant insistió en el poder del juicio sustentado en un acuerdo potencial con los demás, en el que ese sujeto está en comunicación con otros, y en ese acuerdo potencial el juicio adquiere su validez con el requerimiento de liberarse de las "condiciones privadas subjetivas". La mentalidad agrandada en la que se apoya el juicio no puede funcionar en aislamiento o soledad, requiere la presencia de otros en "cuyo lugar debe pensar", ${ }^{37}$ debiendo tomar en consideración los puntos de vista de los demás para así poder "entrar en la acción". ${ }^{38}$ El sentido comunitario se obtiene al agrandar la mentalidad hacia los demás, sin cerrarse en sí. Como afirma Arendt en Between Past and Future "la capacidad de juzgar es una habilidad específicamente política en el sentido exacto denotado por Kant: la habilidad de ver las cosas no sólo desde nuestro propio punto de vista sino en la perspectiva de todos los que acontezca que estén presentes", 39 es condición sine qua non del juicio correcto.

Gracias al juicio se comparte el mundo con los demás; tal habilidad según la filósofa de Könisberg, "los griegos llamaron phrónesis". ${ }^{40}$ Es este término el que permite incorporar y entrelazar a esos hombres en una comunidad y en una cultura, donde el entendimiento compartido es el mínimo esperado de alguien que pretende llamarse hombre. Por eso señala que el hombre es más que hombre si él es también otro hombre, es decir, la percepción de la semejanza que cada uno lleva en sí. Al apreciar las máximas del sensus communis tales como: pensar por sí, pensar en lugar de cada otro y pensar siempre de acuerdo consigo mismo, ${ }^{41}$ es posible confrontar la pluralidad de juicios ${ }^{42}$ y la diversidad de puntos de vista.

${ }^{36}$ Immanuel Kant, Crítica del juicio. México, Porrúa, parágrafo 232; H. Arendt, ed., Lectures on Kant's Political Philosophy, p. 43.

${ }^{37} C f$. H. Arendt, "Crisis en la cultura", en op. cit., p. 233.

${ }^{38}$ Idem.

${ }^{39}$ Ibid., pp. 232 y ss.

${ }^{40}$ Ibid., p. 233.

${ }^{41}$ En estas máximas se hace patente referencia a una dimensión intersubjetiva, aludiendo a una relación con los demás.

${ }^{42}$ Recordando que el juicio en Kant es pensar lo particular como contenido en lo universal (I. Kant, Crítica del juicio, pp. 194-195). 
Este proceso heurístico de buscar los universales a partir de los particulares a través de las máximas señaladas sugiere la idea de un "entendimiento común humano", ya que ese pensar por sí lleva a considerar un modo de pensar libre de prejuicios.

La validez del juicio es, entonces, como ya dijimos, pública, depende siempre de la presencia del otro, en el espacio público en el que se encuentra con los demás. Por eso Arendt señala que

[...] la capacidad del juicio es una habilidad política específica en el propio sentido denotado por Kant, es decir, como habilidad para ver las cosas no sólo desde el punto de vista personal sino también según la perspectiva de todos los que estén presentes; incluso ese juicio puede ser una de las habilidades fundamentales del hombre como ser político, en la medida en que le permite orientarse en el ámbito público, en el mundo común [en el mundo-con-los demás]. ${ }^{43}$

Esa consideración del juicio, para Arendt, se asemeja a la racionalidad práctica, o discernimiento de los griegos, y en concreto de Aristóteles, ${ }^{44}$ quienes la asumen como la principal virtud del hombre de la polis. El discernimiento se arraiga en lo que en general llamamos sentido común y denota la naturaleza del mundo como común donde se comparte-el-mundo-con-los demás a través de la actividad del juicio.

Ahora bien, cultura y política van juntas porque

[...] no es el conocimiento o la verdad lo que en ellas está en juego, sino más bien el juicio y la decisión, el cuerdo intercambio de opiniones sobre la esfera de la vida pública y el mundo común y la decisión sobre la clase de acciones que se emprenderán en él $[\ldots]^{45}$

Cuando las personas llevan a cabo juicios sobre las cosas del mundo que les son comunes, hay otras implicaciones en sus juicios, es decir, las personas por su modo de juzgar se revelan a sí mismas, sobre todo en el campo de la acción y el discurso, esto es, en el campo de las actividades políticas.

La cuestión original postulada por Arendt en su texto "Crisis en la cultura" versa sobre la relación entre la sociedad de masas - que vive en la superficialidad- y la cultura. Esta confrontación se vuelve difícil, ya que el hombre masa

${ }^{43}$ H. Arendt, "Crisis en la cultura", en op. cit., p. 233.

${ }^{44}$ Cf. Aristóteles, Ética nicomaquea. Madrid, Aguilar, 1973, libro VI, p. 1243.

${ }^{45}$ H. Arendt, "Crisis en la cultura", en op. cit., p. 235. 
"independiente de su adaptabilidad, su excitabilidad, carencia de normas, su capacidad de consumo, unida a la incapacidad para juzgar o incluso distinguir, y sobre todo su egocentrismo y esa fatídica alienación [...]", ${ }^{46}$ ese hombre no tiene sus preocupaciones precisas en la cultura. ${ }^{47}$ Arendt sostiene que la sociedad de masas en concreto, no quiere cultura, quiere entretenimiento. ${ }^{48}$ Los productos de la industria del entretenimiento son bienes de consumo que precisan ser agotados. Panis et circenses tienen que ir aparejados, es necesario su constante producción y ofrecimiento para no clausurar el proceso; sus características son la frescura y la novedad. Sin embargo, para Arendt esto es menos amenazante para la cultura que el filisteísmo de la buena sociedad, entendido éste como búsqueda de la utilidad inmediata y de valores materiales, y que se oponen, por consiguiente, a las actividades "inútiles" como las que surgen en la cultura y en el arte. La cultura y aquello que es considerado como cultural, es lo perdurable, estamos en el ámbito público, en el político, donde las cosas ya no se consumen ni se usan, sino que perduran, son durables e inmortales.

El mundo, considerado por Arendt como condición de la humanidad, está implicado con cuestiones políticas. Es ése habitar el mundo específicamente humano a diferencia de un simple estar en la tierra. El mundo incluye el contraste humanista que no se tiene en un ambiente natural donde viven las criaturas biológicas. Ahí en el mundo, somos individuos plurales, donde sólo ese mundo compartido por ellos puede sostener a los individuos juntos, mientras que se mantienen diferentes. Vivir en el mundo significa que un mundo de cosas está entre aquellos que lo tienen en común, es lo que relaciona y separa a los hombres al mismo tiempo.

\section{IV}

Lo que entiende la filósofa alemana por mundo puede resumirse bajo el nombre de cultura. Los trabajos de arte son lo más característico de todas las cosas de lo mundano por su excepcional durabilidad.

En el arte hay una inmortalidad potencial, esa durabilidad es en un sentido cultural, es decir, aquello que puede pasar a generaciones futuras por la belle-

${ }^{46}$ Ibid., p. 211. (Las cursivas son mías).

${ }^{47}$ Cf. Ibid., p. 212.

${ }^{4}$ Arendt entiende por entretenimiento no el tiempo en que estamos libres de todas las preocupaciones y actividades propias del proceso vital y libres para el mundo y su cultura, sino más bien tiempo sobrante, biológico, después de haber cumplido con el trabajo y el descanso. Ese "tiempo vacío es un hiato en el ciclo biológicamente condicionado del trabajo [...]" (H. Arendt, "Crisis en la cultura", en op. cit., p. 217). 
za que portan. Sin embargo surge un problema con la cultura de masas, ya que ella se da en la sociedad, en donde la ligazón entre los hombres es básicamente privada, y su actividad tiene que ver con la producción y el consumo. Los hombres están unidos por las necesidades y deseos. Por eso la sociedad de masas parece una manada uniforme donde lo cultural es la uniformidad de las costumbres y modos de vida. En ese ámbito de lo social se ubican las actividades de producción y consumo, ambos, elementos del proceso vital. La cuestión es que los hombres de esa sociedad de masas como tales tienen que ver con las necesidades de la vida, y traspasan este modelo hacia la política, de modo que se le considera como simple administración de la vida colectiva de la humanidad, y donde los individuos pueden ser vistos como idénticos e intercambiables. La sociedad es la forma en donde sólo el hecho de la dependencia mutua, únicamente por el bien de la vida, es lo que asume significatividad pública. El carácter monolítico de cada tipo de sociedad y su conformismo permite un solo interés o una única opinión, se enraiza en la unidad de la humanidad. Como efecto, la forma natural política que corresponde a esta sociedad no es la democracia, sino la regulación por una burocracia cargada de cuidados nacionalistas. No hay res publica porque la sociedad es un reino deformado, está lejos de ser una arena donde se presenta la pluralidad de individuos. Ésta se presenta reforzando la adherencia a las fluctuantes corrientes de gusto, conducta y opinión y poniendo presión para jugar roles apropiados. Los rasgos sociales son caracterizados por el consumo, por ir de acuerdo a la moda y por mantener un status social.

En este caso, las versiones deformadas de la vida pública se caracterizan por la conformidad, más que por la pluralidad, de ahí que la sociedad sea vista de modo uniforme, monolítico y paternalista.

Arendt entiende por cultura aquella actividad que convierte a la naturaleza en un lugar habitable para la gente, por ello "la actitud del consumo, lleva a la ruina todo lo que toca" ${ }^{49}$ lo único que pervive fuera de referencias utilitarias y funcionales es el arte. ${ }^{50}$ Los valores culturales no son ni de uso ni de cambio, sino que tienen la facultad específica de "captar nuestra atención y conmovernos". ${ }^{51}$ La supervivencia está asegurada, además de que son cosas que existen independientemente de todas las referencias utilitarias y funcionales.

De esta manera, el problema planteado por Arendt en el artículo "Crisis en la cultura" inicia la problemática a través de la pregunta sobre si lo que es verdadero para la sociedad de masas lo es también para la cultura de masas. Consecuentemente de aquí surge la relación problemática entre sociedad y

49 Ibid., p. 223.

${ }^{50}$ Ibid., p. 222.

${ }^{51}$ Ibid., p. 216. 
cultura. ${ }^{52}$ Tal relación fue clara, a decir de Arendt, en el surgimiento del arte moderno que comenzó con una rebelión de los artistas contra la sociedad. Sin embargo, más adelante, la sociedad de masas nace cuando la masa de la población se ha incorporado a la sociedad, en el sentido de "la buena sociedad", al abarcar los sectores de población que tienen medios y tiempo libre, tiempo para dedicarse a la cultura. Así es como la sociedad de masas indica una nueva situación, un nuevo estado de cosas donde la masa dispone también de tiempo libre para la cultura. Por ello, ambos conceptos, sociedad de masas y cultura de masas, parecen fenómenos interrelacionados. Los rasgos de lo que significa el hombre masa son enumerados con ciertas características, a saber, la incomunicación, excitabilidad, carencia de normas, capacidad de consumo, incapacidad de juzgar o distinguir, egocentrismo y alineación.

La preocupación de la filosofía está en lo que sucede con la cultura según las diferentes condiciones de la sociedad y de la sociedad de masas. El productor de esos objetos se vuelve contra la sociedad, de manera que el arte moderno fue consecuencia del sentimiento hostil hacia la sociedad; esto demuestra el antagonismo entre sociedad y cultura.

El gran problema encontrado por Arendt es que el filisteísmo cultural ha hecho perder el pasado en su propio valor, no ha podido ayudarse o apoyarse en ninguna tradición. ¿Cómo rescatar ese pasado sin ese hilo conductor de la tradición que está trunco y roto? La brecha entre ese pasado y el futuro sólo puede solventarse a través del juicio. Esa tradición perdida es el tesoro perdido ya que ella "selecciona y denomina, que transmite y preserva, que indica dónde están los tesoros y cuál es su valor". ${ }^{53}$ La pérdida fue por un fallo en la memoria, de herederos, actores, testigos que fugazmente sostuvieron ese tesoro en su manos, pero lo olvidaron. El recuerdo como forma de pensamiento está desamparado fuera de una estructura de referencia preestablecida, al no haber conexión entre las realidades, no habrá recuerdo. Esa brecha es siempre potencial, sincrónica al hombre en la tierra, y sólo puede indicarse, no puede heredarse ni transmitirse desde el pasado, debe descubrirse de nuevo y hacerse laboriosamente, sólo con la actividad del pensar que conforma ese puente a través de la tradición. La tarea de la mente es entender lo que ocurrió, y esa comprensión es la forma de reconciliación con la realidad, y cuyo fin es estar en paz con el mundo.

Así entonces esa admiración que se tiene hacia las cosas bellas, ese amor a la belleza requiere discernimiento. La banausia indicativa de una mentalidad utilitaria, y el filisteísmo son una amenaza para el campo político, así como para el cultural, al devaluar a las cosas en función de su utilidad.

52 Ibid., p. 209.

${ }^{53} \mathrm{Cf}$. H. Arendt, "Prólogo", en Entre el pasado y el futuro, p. 11. 


\section{Conclusiones}

Se habla de cultura, según la filósofa alemana, cuando su supremacía está asegurada y cuando nos enfrentamos con cosas que existen independientes de referencias utilitarias y funcionales, manteniéndose su calidad siempre igual. En ese momento hablamos de obra de arte. Por eso, cualquier análisis de la cultura deberá partir del fenómeno del arte. Las obras de arte son objetos culturales por excelencia. ${ }^{54}$

El significado de la palabra "cultura" como actividad de transformar la naturaleza en un lugar habitable para las personas, así, la forma en que el hombre se relaciona con las cosas del mundo. La cultura indica que el arte y la política, a pesar de sus conflictos y tensiones, están interrelacionadas e incluso dependen una de la otra, y su interconexión resulta de que ambos son fenómenos del mundo público.

En suma, la cultura indica que arte y política están interrelacionadas, hay dependencia entre ellas y se relacionan entre sí por varios elementos. Entre ellos está el juicio, que supone el lugar común, es el espacio público, y son fenómenos del mundo en su pluralidad, en la libertad y el reconocimiento.

Gracias a elementos tales como el discernimiento y el juicio, la cultura se expresa a sí misma, como lo toma Arendt de la Crítica del juicio y como hemos ya explicado a grandes trazos. El no pensar significa llevar a cabo el diálogo silencioso y solitario, es no regresar nunca a casa ni someter las cosas a examen. No es una cuestión de maldad o bondad, ni de inteligencia o estupidez. ${ }^{55}$ Quien desconoce la relación entre "yo y mí mismo" no le preocupará en absoluto contradecirse a sí mismo, y esto significa que nunca será capaz de dar cuenta de lo que dice o hace, o no querrá hacerlo, ni le preocupará cometer cualquier delito, ya que será olvidado en el momento siguiente. Cuando todo el mundo se deja llevar irreflexivamente por lo que todos los demás hacen o creen, aquellos que piensan son arrancados de su escondite porque su rechazo a participar llama la atención, y por ello su actitud se convierte en una especie de acción. El elemento de purgación contenido en el pensamiento, la mayéutica socrática que saca a la luz las implicaciones de las opiniones no examinadas por tanto las destruye -valores, doctrinas, teorías e incluso convicciones-, es implícitamente político.

El discurso de Arendt es un discurso crítico a partir del cual emprende un análisis de la sociedad contemporánea, detectando procesos de masificación y de banalización, y presentándolos como peligros acechantes. Sólo a través

${ }^{54}$ H. Arendt, "Crisis en la cultura", en op. cit., p. 223.

${ }^{55} \mathrm{Cf}$. H. Arendt, La vida del espíritu, p. 222. 
del pensamiento en el espacio público y cultural, donde los hombres hablan y actúan conjuntamente, tiene sentido la fugaz existencia de los hombres sobre la tierra. Por ello y en palabras de la misma Hannah Arendt podemos terminar diciendo que: "una vida sin pensar es posible, sólo que no consigue desarrollar su propia esencia, no es sólo carente de significado; no es plenamente viva. Los hombres que no piensan son como sonámbulos" .56 "Pensar es, pues, estar auténticamente vivo". ${ }^{57}$

56 Ibid., p. 223.

${ }^{57}$ Ibid., p. 209. 